\section{A reduced incubation period for the destruction of somatic adenosine triphosphate in urine specimens}

\author{
PW MCWALTER, * CA SHARP, GE STERN Department of \\ Bacteriology, University Hospital of South \\ Manchester, Withington Hospital, Manchester \\ $M 208 L R$
}

The use of luciferin-luciferase adenosine triphosphate (ATP) assay as a rapid alternative to cultural methods for bacteriuria screening has been recently reported. ${ }^{12}$ Measurement of bacterial ATP in urine is dependent on effective removal of host-derived somatic ATP. Various methods have been described $^{1-8}$ which destroy or remove unwanted somatic ATP, however, many of the earlier techniques $^{3-7}$ involved complex or time-consuming methodology. The advent of a commercially available somatic nucleotide releasing agent (NRS; Lumac BV, Schaesberg, The Netherlands) has greatly simplified these earlier procedures. The addition of NRS in equal volume to a sample of urine allows the quantitative release of ATP from somatic cells within a period of $10-15 \mathrm{~s}^{8}{ }^{8}$ Subsequent destruction of released somatic ATP using a high quality ATPase enzyme usually involves incubation at room temperature for $45 \mathrm{~min} .^{128}$ This study was carried out to determine whether higher temperature incubation $\left(37^{\circ} \mathrm{C}\right)$ for a reduced period $(20 \mathrm{~min})$ would significantly alter the sensitivity of the screening technique.

\section{Material and methods}

One thousand routine urine specimens were screened for bacteriuria using two preincubation methods for the destruction of somatic ATP, $45 \mathrm{~min}$ at room temperature and $20 \mathrm{~min}$ at $37^{\circ} \mathrm{C}$. The method, equipment and reagents used to carry out the 45 min room temperature preincubation technique have been described. ${ }^{1}$ The same method was used for the rapid technique with preincubation being carried out in a $37^{\circ} \mathrm{C}$ incubator for $20 \mathrm{~min}$. Specimens giving a relative light unit (RLU) value of greater than $711\left(10^{4} \text { organisms } / \mathrm{ml}\right)^{1}$ by either or both techniques were cultured on salt-free McCon- key agar (Oxoid code CM7B) using a standard loop technique $(0.002 \mathrm{ml})$ and examined microscopically for the presence of cells. Culture plates were $\frac{5}{\square}$ examined for significant bacterial growth after over- $\mathbb{\mathbb { Q }}$ night incubation at $37^{\circ} \mathrm{C}$.

\section{Results}

The results of 1000 specimens screened by bioluminescence using both preincubation methods? are shown in the Table. There appeared to be good ${ }_{\sigma}^{\omega}$ correlation between the two methods + $(\mathrm{p}<0.001)$. Nineteen specimens $(1.9 \%)$ giving a bioluminescence-positive result at $37^{\circ} \mathrm{C}$ were negative using the routine room temperature method. All specimens negative by the 20 -minute method were also negative by the 45 -minute method.

\section{Discussion}

The correlation between the two preincubation methods was excellent $(p<0 \cdot 001)$. Variation of results between the two techniques was noted in only 19 specimens $(1.9 \%)$, all of which were bioluminescence-positive using the rapid method $\cong$ but negative using the 45-minute method and gave $\overrightarrow{\overrightarrow{0}}$ no bacterial growth on cultural investigation. Mic- 3 roscopical examination of these specimens showed that all had increased white and/or red cell counts? $\left(>100 / \mathrm{mm}^{3}\right)$. Although the somase would have an increased reaction rate at the higher incubation:temperature, we felt in these cases the period of 3 . incubation was insufficient to allow complete removal of released somatic ATP giving rise to "false-positive" bioluminescence results.

It has previously been shown ${ }^{1}$ that the use of a $1 \times 10^{4}$ organism $/ \mathrm{ml}$ screening threshold removes the occurrence of false-negative (bioluminescencenegative/culture-positive) results. No increase in $\sigma$ false-negative results occurred using the rapid tech- $N$ nique. The 20 -minute at $37^{\circ} \mathrm{C}$ preincubation method reduces the time previously required ${ }^{128}$ to $\sigma$ remove somatic ATP without significantly altering the effectiveness of the reagents involved. The previously described advantages of rapid biolumines- $\stackrel{\infty}{\sim}$ cence bacteriuria screening ${ }^{1-4}$ may be further enhanced by the use of this shortened preincubation technique. These advantages must however be bal- $\mathbb{\Phi}$ anced against the slightly increased number $(1.9 \%) \underset{\mathrm{D}}{\circ}$ of specimens requiring cultural investigation. We feel this rapid preincubation technique is a useful adjunct to bioluminescence bacteriuria screening. 
Results of 1000 urine specimens screened by bioluminescence using two preincubation techniques

\begin{tabular}{lll}
\hline & $37^{\circ} \mathrm{C}$ for $20 \mathrm{~min}$ & Room temp for $45 \mathrm{~min}$ \\
\hline Bioluminescence-negative & $608(60 \cdot 8 \%)$ & $627(62 \cdot 7 \%)$ \\
Bioluminescence-positive & $392(39 \cdot 2 \%)$ & $373(37 \cdot 3 \%)$ \\
\hline
\end{tabular}

We would like to thank Dr DM Jones and Mr P Davis for advice and encouragement, Mrs B Jinks who typed the manuscript and our colleagues who ran the screening system on a routine basis.

\footnotetext{
References

' McWalter PW, Sharp CA. Evaluation of a commercially available semiautomated bioluminescence system for bacteriuria screening. Eur J Clin Microbiol 1982;1,4:223-7.

${ }^{2}$ Ruokenen A, Koskinen M, Leinonen M, Tillikainen A, Vihko R. Detection of urinary infection by rapid luciferase assay of adenosine triphosphate: A comparative study using urine sediment findings and various culture techniques. In: 3rd International Symposium on Rapid methods and Automation in Microbiology, American Society of Microbiology, Washington DC: 1981 .

${ }^{3}$ Johnston HH, Mitchell CJ, Curtis GDW. An automated test for the detection of significant bacteriuria. Lancet 1976;ii:400-8.
}

4 Curtis GDW, Johnston HH. A rapid screening test for bac- teriuria. In: Schram E, Stanley PE, eds. Proceedings of International Symposium on Analytical Applications of Bioluminescence and Chemiluminescence. Westlake Village, California 91361: State Printing Publishing, 1978:448-57.

s Alexander DN, Ederer GM, Matsen JM. Evaluation of an adenosine 5 '-triphosphate assay as a screening method to detect significant bacteriuria. J Clin Microbiol 1976;3,1:42-6.

- Conn RB, Charache P, Chappelle EW. Limits of applicability of the firefly luminescence ATP assay for the detection of bacteria in clinical specimens. Am J Clin Pathol 1975;63:493501.

'Thore, A, Lundin AA, Bergman S. Detection of bacteriuria by luciferase assay of adenosine triphosphate. J Clin Microbiol 1975;1:1-8.

${ }^{8}$ Vanstaen $\mathbf{H}$. Current developments in bioluminescence and chemiluminescence techniques for the medical laboratory. Med Lab World 1979; December;16-23.

Requests for reprints to: Mr PW McWalter, Chief Medical Laboratory Scientific Officer, Withington Hospital, West Didsbury, Manchester M20 8LR, England.

\section{Letters to the Editor}

\section{Hypothermia and pancreatitis}

Dr Foulis' recent study ${ }^{1}$ relating hypothermia with the morphology of the associated acute pancreatitis is of great interest. This work, together with $\mathrm{Dr}$ Foulis' previous comprehensive survey ${ }^{2}$ relating the histological pattern of pancreatitis with various clinical diagnoses may shed some light on the pathogenesis of pancreatitis.

We would like to report certain findings of our own and consider their relevance to Dr Foulis' studies.

We have shown that at temperatures below $37^{\circ} \mathrm{C}$ the inhibitory action of prostacyclin (PGI) on in vitro platelet aggregation is diminished. ${ }^{34}$ Furthermore, the in vitro synthesis of $\mathrm{PGI}_{2}$ by vascular endothelium is decreased at low temperatures. ${ }^{5}$ We have also suggested that at low temperatures the vasodilatory action of $\mathrm{PGI}_{2}$ is diminished. ${ }^{6}$ The raised serum non-esterified fatty acid (NEFA) concentrations reported in hypothermic patients ${ }^{7}$ may be of relevance since we have shown that high NEFA concentrations inhibit vascular PGI synthesis ${ }^{8}$ and accelerate PGI $_{2}$ decay in albumin solutions.'

Hypothermia may thus impair synthesis, increase the rate of decay and diminish the potency of PGI. These changes would result in platelet activation and predisposition to thrombosis and ischaemia. Abnormal platelet behaviour has been demonstrated in an animal study where thrombocytopenia occurred during induced hypothermia. ${ }^{10}$ An increased incidence of thrombotic phenomena in patients with hypothermia is evident from Dr Foulis' own observations and from the literature he cites. ${ }^{1}$

Ischaemic damage to the pancreas may occur in hypothermic patients as a result of platelet activation (as discussed above) or of "microcirculatory shock" as suggested by Dr Foulis. Such damage to the pancreas may cause the release of various enzymes. Amongst these, elastase, is thought to play a role in the destruction of vessel walls in patients with pancreatitis." Damage to vascular endothelium would further impair $\mathrm{PGI}_{2}$ synthesis and expose deeper layers of vessels which may initiate platelet aggregation due to their collagen content. The release of trypsin is thought to activate the coagulation cascade, enhancing the ten- 